\title{
Significados e usos sociais da expertise na implementação de políticas públicas de gestão ambiental'
}

\author{
Wilson José Ferreira de Oliveira \\ Doutor em Antropologia Social (Universidade Federal do Rio Grande do Sul) \\ Professor da Universidade Federal de Sergipe \\ Aracaju, Brasil \\ wjfo2001@ig.com.br
}

\begin{abstract}
Resumo Este artigo examina os significados e as lógicas sociais da utilização de recursos de expertise nas políticas públicas de gestão ambiental. Os procedimentos analíticos concentraram-se numa análise da história social do setor de proteção ambiental e na investigação da diversidade de esferas e de redes sociais articuladas às trajetórias familiares, escolares, militantes e profissionais dos atores envolvidos com a execução da política de silvicultura no Rio Grande do Sul. Os resultados obtidos demonstraram que os significados e a utilização da expertise em tal situação estão associados a padrões diversificados de reconversão da formação e do exercício profissional em diferentes esferas de atividade, com base nos vínculos anteriores e/ou simultâneos estabelecidos com redes diversificadas de organizações e "movimentos sociais".
\end{abstract}

Palavras-chave: políticas públicas; expertise; redes sociais; reconversão profissional.

\section{Apresentação}

$\mathrm{N}$ OS ÚlTIMOS ANOS TEM HAVIDO um grande número de discussões, debates, manifestações e protestos relacionados ao plantio de eucalipto no Brasil, mobilizando a imprensa, setores empresariais, agências governamentais, partidos políticos, organizações e movimentos sociais diversificados. A questão do "modelo de desenvolvimento" mais adequado ao país constitui um aspecto comum às diferentes posições em confronto: de um lado, os que são contrários e salientam os "impactos ambientais" de tal atividade, que se constituiria uma ameaça a um modelo de desenvolvimento que integre as dimensões ambientais, sociais, culturais, políticas e econômicas, e, do outro, os que se manifestam favoráveis, destacando a importância de sua expansão como "alternativa de desenvolvimento econômico". Quando se examina o que está sendo produzido na universidade sobre o assunto, o que se observa é uma grande continuidade entre o universo acadêmico e o militante, de modo que a categoria militante "desenvolvimento sustentável" também está no

1 Este artigo é uma versão modificada do trabalho apresentado no IX Congresso Argentino de Antropologia, realizado entre os dias 5 e 8 de agosto, em Posadas, Misiones, Argentina, na Mesa 13: Antropología Política, Comissão 2: Expertos y Militantes en la Acción Política. Emergencia de Nuevas Elites Dirigentes. As pesquisas que deram origem a este trabalho foram financiadas pela Capes, com bolsa de doutorado, CNPq, através da concessão de recursos para despesas com capital, e Fapergs, com a concessão de uma bolsa de iniciação científica. 
centro dos debates acadêmicos. Nesse sentido, as abordagens utilizadas pela maioria dos trabalhos têm como objetivo principal demonstrar os "impactos ambientais" da expansão do plantio de eucalipto para a referida localidade ou região. Outro conjunto de abordagens sobre tais empreendimentos prioriza análises excessivamente "macroestruturais", que associam as origens e os desdobramentos de tais atividades à chamada "lógica de expansão do capitalismo", que hoje se mostra como um sistema que paralisa e captura os atores sociais no interior de "alternativas infernais", deixando-os sem escolha: ou resignação ou denúncia impotente diante da "guerra econômica incontornável" (Acselrad, 2007, p. 2).

Sem descartar a importância da dimensão estrutural na análise de tal questão, um dos aspectos que tem sido pouco salientado pela literatura pertinente diz respeito à apreensão das dinâmicas e lógicas "locais" que tornam possíveis tais empreendimentos. Este texto pretende demonstrar que tais lógicas não podem ser reduzidas a simples "efeitos" de tendências "macroestruturais" e se insere numa perspectiva de dar conta das dimensões sociais, políticas e culturais "locais" associadas ao surgimento e à realização de tais empreendimentos. Um dos pontos de partidas relevante à apreensão dessas dimensões "locais" consiste na investigação dos processos de formulação e implementação de políticas públicas de gestão ambiental e suas relações com as ações concretas de lideranças, organizações e movimentos sociais diversificados. Desse modo, as indagações que estão no centro de nosso interesse dizem respeito às questões mais gerais referentes à investigação das condições sociais, políticas e culturais que tornam possíveis o plantio do eucalipto nessas situações: quais são os mecanismos estruturais e institucionais que operacionalizam a realização de tais atividades? Quem são os atores envolvidos? Quais os recursos que eles mobilizam e a que vínculos e esferas sociais tais recursos remetem?

Um dos problemas pertinentes ao tratamento sistemático de tais indagações diz respeito aos usos da formação técnica e das competências de expertise nas dinâmicas de formulação e de operacionalização de políticas de gestão ambiental. Esse aspecto já tem sido amplamente destacado pela literatura nacional e internacional sobre as condições e dinâmicas de implantação de políticas públicas de gestão ambiental. Isso porque tal literatura tem se centrado no papel preponderante da formação técnica e científica e na utilização de competências de expertise, adquiridas através da formação universitária, nos processos de formulação e de implementação de tais políticas. Segundo tais abordagens, cada vez mais são mecanismos, dispositivos e atores vinculados ao universo da técnica e da ciência os que assumem um papel destacado na construção e na administração das reivindicações e dos problemas ambientais (Lascoumes, 1994). Em consonância com tais abordagens, outro contingente enorme de trabalhos enfatizou que uma das consequências principais dessa imposição da expertise nas políticas ambientais têm sido a institucionalização e a profissionalização do próprio ativismo ambientalista. Nesse sentido, demonstra-se que a participação regular das associações em instâncias formais de proteção ambiental (conselhos, fóruns, comitês etc.) implicou o recrutamento de militantes e dirigentes dotados de elevada formação técnica e científica e a imposição de competências de expertise como um dos principais recursos militantes nas intervenções públicas de tais organizações (Anquentin, 2002; Gallet, 2002; Rootes, 1999). No caso brasileiro, esse tipo de interpretação se faz presente naqueles trabalhos que enfatizam a maior difusão e institucionalização da problemática ambiental nas mais diferentes organizações e setores da sociedade e que destacam a intensificação do processo de profissionalização das organizações ambientalistas e de contratação de técnicos como forma de legitimação de suas atividades e intervenções públicas (Loureiro e Pacheco, 1995). Todavia, na literatura nacional sobre as políticas públicas de gestão ambiental ainda predominam um forte engajamento e um comprometimento com as causas ambientais e com os modelos de "desenvolvimento sustentável". Como salientam Alonso e Costa (2002), a partir do final da década de 1980, os estudos sobre essa temática passaram a se concentrar no "desenvolvimento sustentável" e foram produzidos "fora das ciências sociais" por especialistas das ciências naturais e das humanidades, tais como filósofos, geógrafos, demógrafos, biólogos, agrônomos, jornalistas, entre outros, mas mantendo um "viés político, engajado". Desse modo, um aspecto que, até o momento, não tem sido devidamente explorado pelas investigações realizadas sobre as políticas públicas de gestão ambiental no Brasil, e sobre o programa de expansão do eucalipto em particular, diz respeito às relações entre os "modelos de desenvolvimento" invocados pelas lideranças em confronto, os mecanismos e processos políticos e institucionais postos em operação e as trajetórias e recursos sociais das organizações e dos atores vinculados às dinâmicas de formulação e execução de tais políticas.

Essa formulação da questão de pesquisa se insere numa problemática de investigação mais geral referente às condições de emergência e às dinâmicas do ambientalismo no Brasil e constitui um desdobramento de uma pesquisa anterior sobre as lógicas sociais de engajamento no ambientalismo entre 1970-2005 (Oliveira, 2005) e de duas investigações ainda em curso: uma, sobre as dinâmicas de fabricação e de utilização de manifestações e protestos públicos na defesa de causas ambientais (Oliveira, 2007a); outra, sobre os processos de produção da política de expansão do eucalipto no Rio Grande do Sul (Oliveira, 2007b). Esse conjunto de pesquisas tem nos colocado diante do de- 
safio de considerar os significados e os usos da expertise em suas relações com os processos diferenciados de configuração da formação escolar e profissional, da burocracia estatal, assim como da própria atividade militante. Neste artigo, pretende-se evidenciar a hipótese de que os significados e a utilização de competências de expertise na defesa de causas ambientais estão associados a padrões diversificados de reconversão da formação e do exercício profissional em diferentes esferas de atividade, com base nos vínculos anteriores e/ ou simultâneos estabelecidos com redes diversificadas de organizações e "movimentos sociais". Entre tais esferas destacam-se: a administração pública e a burocracia estatal, as universidades e os centros de pesquisa, os serviços de assessoria e consultoria, os cargos de direção em associações e ONGs ambientalistas, bem como em sindicatos e organizações de defesa de categorias profissionais, em partidos políticos etc. Essa forte imbricação da formação técnica e profissional com o engajamento político, através da inserção em diversas redes de organizações e "movimentos sociais", está na base de dois aspectos principais: por um lado, da estreita ligação entre as dinâmicas políticas e institucionais, vinculadas aos processos de formulação e implementação de políticas de gestão ambiental; por outro lado, dos diversificados recursos acumulados pelos atores interessados em sua elaboração e execução, com base nos vínculos estabelecidos com esferas sociais diversas no decorrer de seus itinerários familiares, escolares, profissionais, políticos e militantes. Nesse sentido, demonstra-se que a inserção e os respectivos vínculos com redes e esferas sociais distintas têm um peso significativo na conformação da base de recursos utilizados pelos formuladores da política de silvicultura. Quanto a isso, trata-se de uma situação muito próxima àquelas em que a constituição de organizações e agências governamentais voltadas para a proteção ambiental é fortemente dependente da esfera estatal e da dinâmica político-partidária em termos de suas formulações ideológicas e de seus recursos humanos, organizacionais e financeiros (Jimenez, 1999).

Tal hipótese está embasada no princípio de que a ocupação de cargos e posições profissionais não constitui um resultado direto da formação escolar e universitária adquirida, sendo antes mediada por dinâmicas estruturais e objetivas, bem como por recursos, disposições e concepções constituídas no transcurso de diferentes tipos de socialização (familiar, escolar, política, profissional etc.) (Bourdieu, 1979; Bourdieu \& Boltanski, 1998; Bourdieu, 1998). Uma das alternativas abertas pela análise do militantismo na defesa de causas consiste justamente em considerar tal atividade como resultado de "investimentos sociais múltiplos" e da participação anterior ou simultânea dos atores em um conjunto diversificado de "atividades sociais" (Collovald, 2002; Coradini, 2002; Lecheien, 2002). Desse modo, a análise das modalidades de ocupação de cargos e funções de expertise em instâncias de formulação de políticas ambientais pode ser tomada como uma situação exemplar para a investigação das condições e lógicas sociais de reconversão da formação escolar em competências profissionais. Ela está respaldada também por diferentes estudos que têm salientado a importância do "plano político" na constituição dos recursos que sustentam as dinâmicas de constituição e de ação dos grupos sociais na sociedade brasileira (Pécaut, 1990; Coradini, 1998; Dezalay \& Garth, 2002; Conniff, 2006; Love \& Barickman, 2006). Tais estudos têm evidenciado que, no caso brasileiro, as concepções e as práticas associadas à formação e ao exercício "profissional" em diferentes esferas de atividade exigem, principalmente, a capacidade de estabelecer um vínculo duradouro entre o "conhecimento escolar" e a "realidade", de modo que a prática profissional é concebida como algo que resulta quase sempre da utilização instrumental de competências adquiridas através da formação escolar e universitária, com fins de politização nas mais diferentes esferas sociais.

Para evidenciar isso, serão examinadas as condições e as lógicas sociais que respaldam os usos e a reconversão da formação escolar e universitária para a ocupação de cargos e funções dirigentes em organizações e instâncias de formulação de políticas de proteção ambiental, focalizando as concepções que fundamentam as definições da formação técnica, assim como os tipos de recursos e de vínculos sociais e políticos associados ao seu exercício. O material utilizado como fonte de informação consistiu, primeiramente, de artigos de jornais de âmbito regional, informações disponíveis em sites de associações, redes de ONGs, secretarias, conselhos e comitês estaduais de proteção ambiental, sites de notícias ambientais e publicações sobre a história do ambientalismo no Rio Grande do Sul e no Brasil, com o intuito de elaborar uma história social da constituição do "setor" de proteção ambiental no Rio Grande do Sul. Em segundo lugar, foram realizadas entrevistas biográficas com ativistas das principais ONGs ambientalistas do estado, com "técnicos" que atuam em agências governamentais de proteção ambiental e com aqueles que prestam serviços de assessoria e consultoria a empresas que atuam no "setor" de proteção ambiental. Os procedimentos metodológicos utilizados para o conjunto das entrevistas concentraram-se na investigação das trajetórias familiares, escolares, ocupacionais e militantes que os conduziram ao ambientalismo, no exame dos significados e das modalidades de uso da formação escolar associados à sua atuação e na análise da diversidade de esferas e de redes sociais que contribuem para a aquisição e a reconversão dos recursos que fundamentam suas concepções e práticas militantes e profissionais. O material obtido através de tais procedimentos conduziu à identificação de diferentes padrões de carreiras que conduzem à atuação profissional na "área do meio ambiente". 
Agendas internacionais, mecanismos institucionais e "setor" de proteção ambiental

A existência de organismos e agências governamentais destinados à proteção ambiental no Brasil não é tão recente como geralmente se afirma. No final do século XIX foram criados os primeiros parques nacionais e, durante a implantação da Constituição de 1934, foram formulados o Código de Águas e Minas e o primeiro Código Florestal Federal Brasileiro. Essas primeiras iniciativas foram inspiradas - e também respaldadas por elas - em políticas adotadas nos "Estados Unidos que, desde 1900, estavam vivendo um período de intensa regulamentação e elaboração de linhasmestras políticas para controlar o uso dos recursos minerais e florestais" (Svirsky e Capobianco, 1997).

Essa influência de problemáticas e de políticas orientadas pelas agendas internacionais é um traço característico também do início da estruturação administrativa das agências governamentais responsáveis pela defesa ambiental durante a década de 1970. Isso porque a criação das primeiras agências nacionais esteve diretamente vinculada à participação do Brasil na I Conferência das Nações Unidas para o Ambiente Humano, em Estocolmo, no ano de 1972. Nessa conferência, a posição inicial do governo brasileiro, juntamente com outros países em desenvolvimento, de priorizar o "crescimento acelerado em detrimento de questões ligadas à preservação do meio ambiente", foi objeto de pressões de grupos ambientalistas estrangeiros (Loureiro e Pacheco, 1995, p. 138). Tal posição tratava a problemática ambiental como "a antítese do desenvolvimento almejado" com o argumento de que "a principal poluição era a miséria" e de que "a proteção ao meio ambiente era uma preocupação inventada pelos países ricos para pôr obstáculos à industrialização do Terceiro Mundo" (Menezes, 1997). Diante das críticas e pressões de instâncias internacionais geradas por essa posição do governo brasileiro, e com o intuito de se conformar às diretrizes formuladas por tais instâncias, evitando ficar numa posição de vulnerabilidade diante da obtenção de empréstimos e investimentos vindo de fora do país, foi criada em 1973 a Secretaria Especial do Meio Ambiente (Sema). Além desse objetivo inicial, "não havia qualquer definição clara e objetiva de uma política ambiental para o país a ser conduzida por essa secretaria. Foi atribuída a ela apenas um rol de objetivos de difícil operacionalidade" (Menezes, 1997, p. 80).

Essa combinação de adequação às agendas internacionais com grandes indefinições institucionais e uma estruturação precária é um aspecto que predomina ao longo da existência e do funcionamento das estruturas administrativas de proteção ambiental. Ela era o órgão normativo e de coordenação da área de meio ambiente no país, estando vinculada inicialmente ao Ministério da Saúde e à Política Nacional de Saneamento. Em consonância com isso, seus objetivos estavam orientados para a conservação dos recursos ambientais e para o controle da poluição industrial. No entanto, sua criação e seu funcionamento ocorreram de forma desarticulada de órgãos mais antigos como o Instituto Brasileiro para o Desenvolvimento Florestal (IBDF), a Superintendência para o Desenvolvimento da Borracha (Sudeheva) e a Superintendência do Desenvolvimento da Pesca (Sudepe), que tinham atribuições tanto normativas quanto financiadoras de projetos de reflorestamento e que, no caso do segundo, estavam ligados ao desmatamento de extensas áreas da Floresta Amazônica. É somente em 1989, ou seja, dezesseis anos após sua criação, que a Sema passa a fazer parte, juntamente com esses outros órgãos, de uma estrutura unificada, formando o Instituto Brasileiro do Meio Ambiente e dos Recursos Renováveis (Ibama). Além dessas indefinições institucionais, a existência de tal secretaria foi marcada por uma grande precariedade em termos de recursos humanos e materiais: dispunha de apenas três técnicos, dada a falta de eficácia e de efetividade de suas ações institucionais. Desse modo, tinha de funcionar em aliança com os estados e delegando competências e funções a estes, em contraste com a lógica centralizadora que predominava em nível federal nesse período e que se fazia presente na concepção da própria estruturação ambiental, à qual deveria funcionar sob a forma de um sistema coordenado por um organismo central (Andreoli, 1992).

À expansão do ambientalismo para diferentes espaços sociais, durante a década de 1980, corresponderam a ampliação do papel do Ministério Público como defensor dos "direitos difusos", a criação de secretarias, órgãos públicos e conselhos de meio ambiente e a exigência de realização de estudos e relatórios de avaliação de impactos ambientais (EIA-Rima) na implantação de atividades que apresentem riscos e impactos ambientais, os quais devem ser apresentados e debatidos em audiências públicas. É também nesse período que foi instituída a Política Nacional do Meio Ambiente por intermédio da Sema e que surgiu o Ministério do Desenvolvimento Urbano e Meio Ambiente, com o objetivo de elaborar arranjos institucionais novos para a área ambiental. Dessa forma, foi criado o Sistema Nacional do Meio Ambiente (Sisnama), que procurava articular as instituições ligadas à proteção ambiental nos níveis federal, estadual e municipal e que possibilitava a participação de associações e organizações não governamentais nessas diferentes instâncias na implantação da política ambiental.

No entanto, é somente no ano de 1992, quatro meses após a realização da Conferência das Nações Unidas sobre Meio Ambiente e Desenvolvimento, na cidade do Rio de Janeiro, que foi criado o Ministé- 
rio do Meio Ambiente. Dada a carência de condições institucionais dos órgãos federais para atuar no âmbito estadual, o resultado foi estimular os estados a criar suas próprias estruturas. Contudo, o processo de estabelecimento dos organismos estaduais e municipais responsáveis pela política ambiental ocorreu de forma paralela e desarticulada dos desdobramentos salientados no nível federal. Isso porque a implantação de órgãos estaduais de meio ambiente esteve inicialmente vinculada à formulação do II Plano Nacional de Desenvolvimento (II PND), que atribuía aos estados e municípios competências específicas no controle da poluição causada pelo funcionamento das indústrias, de modo que a atuação de tais organismos estaduais restringia-se ao tratamento dos problemas já existentes causados pela poluição industrial. Além disso, as diretrizes contidas no II PND eram muito fragmentadas, tinham um caráter essencialmente corretivo e não possibilitavam uma organização de conjunto. Isso resultou na expansão de estruturas descentralizadas em relação ao âmbito federal e muito marcadas pelo contexto próprio de cada estado ou região. Em decorrência dessa acentuada descentralização e fragmentação dos âmbitos municipal, estadual e federal na implantação de políticas ambientais, os conflitos entre as agências governamentais foram constantes e ampliados ainda mais com a entrada em vigor da Constituição Federal de 1988, a qual introduziu a ação concorrente da União, dos estados e municípios como corresponsáveis pela garantia da qualidade ambiental (Loureiro e Pacheco, 1992). Como salienta Andreoli (1992, p. 19),

Essas indefinições, aliadas às áreas de vácuo institucional causadas pelo avanço de legislação sem a respectiva estruturação dos órgãos, e aquelas sobreposições já citadas estabeleceram, em alguns casos, dificuldade de identificação da estrutura responsável, por parte da sociedade civil.

No caso do Rio Grande do Sul, as agências estaduais de proteção ambiental também foram inicialmente vinculadas à problemática da poluição, através da Secretaria Estadual de Saúde. A Coordenadoria de Controle e Equilíbrio Ecológico (CCEE) foi o primeiro órgão do estado ligado à preocupação com a proteção ambiental, passando a fazer parte da Secretaria de Saúde e Meio Ambiente nos anos de 1980. Nesse mesmo período, foi criado o DMA, chamado Departamento de Meio Ambiente, cuja atuação direcionava-se à fiscalização da indústria coureira e, em 1990, foi transformado na Fundação Estadual de Proteção Ambiental (Fepam). O desenho institucional atual dos órgãos estaduais de proteção ambiental é muito recente, tendo início apenas no ano de 1999, com a criação da Secretaria Estadual do Meio Ambiente. Ela conjugou os órgãos que estavam em outras secretarias: a Fundação de Zoobotânica (FZB) e o Departamento de Florestas e Áreas Protegidas (Defap), que eram da Secretaria da Agricultura e Abastecimento; a Fundação Estadual de Proteção Ambiental que era da Secretaria da Saúde, e o Departamento de Recursos Hídricos (DRH), que fazia parte da Secretaria de Obras e Saneamento.

Todavia, essas mudanças no arcabouço legal e nas estruturas administrativas de proteção ambiental do estado não devem ser consideradas como sinônimo da imposição de uma racionalidade técnica e científica na gestão das políticas ambientais nem também da influência e constituição de uma categoria profissional que passa a liderar tal "setor" (Muller, 1995; Marques, 2003). Antes disso, é a constante utilização da formação técnica e profissional através de vínculos políticos partidários que constitui a base principal dos recursos que conduzem aos cargos administrativos no setor de proteção ambiental. Como consequência da imbricação da formação escolar e profissional com o engajamento político em diversificadas redes de organizações partidárias, a constante mudança política e eleitoral, externas aos interesses e às lógicas próprias do setor, representa um dos fortes ingredientes da dinâmica de funcionamento de tais instituições. Um breve exame das mudanças nos principais postos de direção da Sema e da Fepam é um bom indicador do quanto os cargos mais importantes são ocupados pela combinação de critérios político-partidários e formação profissional.

Quanto a isso, observa-se que o padrão mais recorrente de ocupação e substituição dos cargos é constituído pelos casos em que o ingresso em tais postos não foi precedido pela atuação em cargos vinculados à área de meio ambiente, seja na administração pública, seja na área privada. Isso é evidente no caso de dois secretários da administração do PMDB, pois um era técnico contábil e o outro médico especializado em cirurgia plástica, formado pela Universidade Católica de Pelotas. Esse também é o padrão principal de ocupação e sucessão dos cargos principais da Sema na atual administração estadual, na qual o atual secretário é promotor do Ministério Público Estadual, sem experiência anterior na área ambiental. O outro padrão igualmente presente é o representado pelos casos em que a entrada na Sema foi precedida pela atuação em cargos de chefia na "área do meio ambiente" em outras administrações do mesmo partido. Esse é o caso do primeiro secretário de meio ambiente que permaneceu à frente da referida pasta durante toda a gestão do PT, desde a sua criação em 1999. Ele só deixou o cargo com a derrota eleitoral do partido, mas, como este conquistou o governo federal, passou a ocupar o cargo de secretário especial do Ministério do Meio Ambiente na administração federal. Tal padrão pode ser encontrado no governo seguinte, comandado pelo PMDB. Todavia, nesse caso, hou- 
ve uma maior alternância na ocupação das principais pastas da Sema. Dos quatro secretários que ocuparam a pasta principal da secretaria durante essa administração, apenas dois tinham uma atuação anterior na área de meio ambiente: o primeiro cursou mestrado na área e já havia ocupado a pasta da Secretaria de Meio Ambiente de Santa Cruz; o segundo, que foi chamado no último ano de governo do $\mathrm{PMDB}$, já tinha atuado na Secretaria do Meio Ambiente e Saúde de Porto Alegre e na assessoria do meio ambiente na Prefeitura Municipal de Nova Prata. Por fim, em apenas um caso ocorre a ocupação do cargo por "funcionários de carreira" da própria administração estadual, com experiência "técnica" na área. Trata-se da secretária que era formada em biologia e museologia, tinha mestrado em botânica e era doutora em ciências pela UFRGS, além de ser servidora da Fundação de Zoobotânica do Rio Grande do Sul.

Constatação semelhante se encontra quando são analisadas as disputas a respeito das próprias instâncias e das esferas institucionais e político-administrativas de discussão e de decisão quanto à adoção de políticas ambientais, bem como dos procedimentos e critérios que deverão ser implementados para sua execução. Um bom exemplo disso são os confrontos em torno do zoneamento e do licenciamento ambiental da silvicultura no Rio Grande do Sul. Isso porque, durante o governo do PMDB, ficou acordado entre a Sema, Fepam e Ministério Público Estadual que enquanto esse zoneamento estivesse sendo elaborado pelos técnicos da Fepam, além de especialistas representantes de outros setores, o licenciamento para a atividade de silvicultura vigoraria com base em um Termo de Ajustamento e Conduta (TAC) entre os órgãos responsáveis. As datas definidas foram até 31 de dezembro de 2006 para a entrega do zoneamento e 31 de março para ele ser discutido no Consema. No entanto, o documento sobre o zoneamento estava incompleto nessa data, provocando um atraso. A data limite do TAC expirou e com isso vieram à tona ameaças de desistir dos investimentos, demissões de trabalhadores das empresas que prestam serviços terceirizados às empresas de celulose, acusações de morosidade por parte da governadora e uma ampla discussão com acusações à secretaria na mídia. Na reunião do Consema de 19 de abril de 2007, o então diretor presidente da Fepam, nomeado pela atual gestão, iria pedir uma prorrogação da data do TAC, argumentando que isso já estava previsto no que havia sido assinado antes. Esse novo TAC acabou resultando no seu pedido de saída da Fepam. Isso porque esse TAC, segundo políticos e empresas, era muito restritivo, não possibilitando uma "flexibilização", com a retirada da obrigatoriedade de seguimento do zoneamento que ainda não tinha sido discutido no Consema. Por outro lado, o documento elaborado pela Fepam também recebeu críticas por conter muitas restrições com relação às áreas que poderiam ser plantadas, alegando-se que não estavam sendo levados em consideração fatores ecológicos e econômicos e, dessa forma, deixando-se de fora os empreendimentos dessas fábricas em muitas cidades.

Para viabilizar as reivindicações dos empresários e de deputados alinhados ao atual governo estadual, a secretária da Sema foi substituída pelo procurador do Ministério Público Estadual, que já tinha sido presidente da Associação do Ministério Público do RS e exercido as funções de secretário de Estado da Justiça e Segurança. Além disso, também o diretor da Fepam foi demitido e, em seu lugar, foi nomeada uma bacharela em economia com mestrado em controladoria e que tinha sido diretora do Tribunal de Justiça do RS e diretora-geral da Secretaria de Segurança Pública. Em reação às medidas adotadas pela Sema e Fepam, que aprovavam as reivindicações dos setores empresariais e dos políticos defensores da expansão do eucalipto, os ambientalistas entraram com várias ações na justiça. Uma delas foi ajuizada pela juíza-substituta da Vara Ambiental da Justiça Federal de Porto Alegre/RS, através de uma liminar que transferia da Fepam para o Ibama o licenciamento das atividades de silvicultura, proibindo, inclusive, a plantação do que já tinha sido aprovado por EIA/Rima. Sua argumentação foi que havia um "desvio de finalidade na atuação da Fepam" ao adotar critérios que comprometiam "os princípios de prevenção e precaução, indispensáveis à garantia de difusos interesses socioambientais", e que o Ibama, por ser órgão federal, "estaria afastado de pressões locais". Algumas semanas depois, a desembargadora federal e presidente do Tribunal Regional Federal (TRF) suspendeu a liminar que impedia a Fepam de emitir qualquer tipo de licenciamento ambiental para empreendimentos ligados à silvicultura no Rio Grande do Sul, argumentando que a liminar anterior incorria no "risco indiscutível de grave lesão à ordem pública e à segurança jurídica".

Tais conflitos e redefinições institucionais evidenciam o quanto os critérios e procedimentos postos em prática na implementação de políticas ambientais resultam da estrutura das redes sociais que convergem para tais políticas e de suas vinculações com clivagens político-ideológicas. De um lado, redes sociais que vinculam militantes de associações ambientalistas e lideranças de movimentos sociais diversificados e de partidos políticos ditos de "esquerda" e, mais precisamente, do Partido dos Trabalhadores; do outro, redes sociais estruturadas em torno de membros de ONGs e políticos que mantêm vínculos com o "mundo empresarial". O confronto entre membros dessas diferentes redes que convergem para as políticas ambientais está na origem das mudanças constantes dos critérios e recursos mobilizados nas diferentes esferas da administração pública. A permeabilidade de tais redes, 
relativamente externas aos interesses específicos da "comunidade de políticas públicas" e do "setor" de proteção ambiental, no funcionamento cotidiano do Estado, constitui uma das principais razões da dificuldade para a imposição das definições e das regras a serem aplicadas na implementação de políticas ambientais com um mínimo de autonomia. Isso porque à multiplicidade de referenciais e de definições de ordem distinta corresponde uma enorme variação dos mecanismos e procedimentos institucionais. Em decorrência disso há uma diversidade muito grande dos interesses em jogo e dos recursos mobilizados pelos principais responsáveis pela formulação e pela implementação de políticas de gestão ambiental em função de sua inserção em redes sociais diversificadas. Como exemplifica o caso do licenciamento do eucalipto, muito mais do que um conflito que se desenvolva internamente nas redes de organizações, de técnicos e de lideranças que fazem parte do "setor" de proteção ambiental, as medidas e procedimentos em relação ao processo de zoneamento e licenciamento ambiental trouxeram à tona inúmeras organizações e lideranças atuantes em diferentes ordens sociais, bem como o conflito entre as administrações municipais, estaduais e federais.

Desse modo, um breve recuo na constituição das instituições de administração da proteção ambiental parece nos colocar diante de modelos de formulação e implementação de políticas públicas diferenciados daqueles apresentados através das noções de "redes de comunidades de políticas públicas" (Marques, 2003) ou de "setorialização" da ação pública, bem como das análises que pressupõem a existência de uma "liderança profissional e técnica" que controle com legitimidade as políticas formuladas (Muller, 1995). Tal exame nos coloca diante de uma situação semelhante aos casos caracterizados tanto pela grande instabilidade na estrutura e composição das "redes de comunidade" das políticas públicas quanto pela frequência de vínculos e recursos mobilizados que resultam da inserção dos formuladores das políticas públicas com esferas sociais diversificadas e exteriores aos interesses e lógicas próprias de funcionamento do setor (Coradini, 1994). Isso porque a existência e o funcionamento das instituições administrativas e burocráticas de formulação e implementação de políticas de proteção ambiental estão profundamente imbricados com clivagens político-ideológicas relacionadas à dinâmica da política partidária. Sendo assim, os vínculos anteriores e simultâneos dos formuladores de tais políticas com organizações partidárias ou facções políticas regionais e locais são muito mais fortes do que os interesses e lógicas próprias da esfera burocrática e administrativa. Além disso, eles estão respaldados por recursos acumulados através da inserção em um conjunto diversificado de esferas de atividade, no decorrer de seus itinerários familiares, escolares, profissionais e políticos.

\section{Escolarização, engajamento político e usos do conhecimento técnico na formulação e operacionalização de políticas ambientais}

Um dos procedimentos pertinentes à apreensão da diversidade de recursos e de vínculos que regem o uso da competência técnica nas políticas de proteção ambiental é o exame dos principais padrões de carreiras que conduzem à ocupação de cargos e funções profissionais como "ambientalista" em diferentes esferas sociais. Tal utilização da noção de carreira procura dar conta das disposições favoráveis à participação política em suas relações com as desigualdades de condições de origem e os respectivos capitais (sociais, econômicos, políticos e culturais) dos diferentes agentes sociais (Bourdieu, 1979, 1980). Mas ela se centra também no exame dos pertencimentos múltiplos dos atores sociais e dos diversos contextos relacionados aos processos de socialização que resultam na constituição e na modificação das disposições que conduzem à participação em mobilizações coletivas (Fillieule, 2001). Trata-se, portanto, de integrar a perspectiva diacrônica na investigação dos processos de socialização que conduzem à atuação técnica na formulação de políticas ambientais e de apreender os padrões de entrelaçamento de diferentes "ordens de experiência" (familiares, escolares, militantes e profissionais) vinculadas a esse tipo de atuação. Dessa forma, tal análise contribui para a compreensão do exercício de funções técnicas em instâncias de proteção ambiental como resultado de "investimentos sociais múltiplos" (Collovald, 2002). Isso implica a investigação das intersecções das disposições associadas à atuação individual, tanto com os processos de socialização decorrentes de suas condições de origem e trajetórias familiares quanto com as experiências e os diversos contextos interacionais interligados à biografia individual. De maneira mais precisa, trata-se de considerar a multiplicidade de esferas e de redes sociais associadas ao engajamento, bem como a participação anterior ou simultânea em um conjunto diversificado de atividades, organizações e movimentos sociais. Com base nisso, podem-se diferenciar três padrões principais de usos do conhecimento técnico na discussão, na elaboração e na implementação de diretrizes e critérios referentes ao licenciamento da silvicultura através da instalação das empresas de celulose.

Em primeiro lugar, destaca-se o padrão de carreira representado pelos ativistas das ONGs ambientalistas que fazem parte do conselho e das câmaras técnicas vinculadas à discussão e à elaboração da proposta de licenciamento e de zoneamento ambiental para a silvicultura na região. Com inúmeras diferenças entre o conjunto dos ambientalistas, pode-se falar de um 
padrão que se caracteriza pelo predomínio de indivíduos com origens sociais médias e heterogêneas, que têm como principal base de recursos as inserções e os vínculos estabelecidos no decorrer de seus itinerários familiar, escolar e profissional com organizações e "movimentos sociais" diversificados (estudantis, sindicais, partidários, religiosos etc.) e cujas concepções de participação política remetem à politização das mais diferentes esferas de atividade com base nesse intenso militantismo (Oliveira, 2008). Nesses casos, a articulação da formação universitária com a participação em organizações estudantis e, posteriormente, em partidos políticos representa um dos ingredientes principais de seus itinerários escolares. Além disso, tais vínculos anteriores geralmente se desdobram no militantismo partidário ou associativo através da ocupação de cargos ou funções de representação em instâncias de proteção ambiental.

Um exemplo típico desse padrão de carreira é a que resulta do intenso militantismo em organizações estudantis e partidárias e da articulação do engajamento associativo com a ocupação de cargos e funções remuneradas na administração pública e na burocracia estatal com base nos vínculos estabelecidos na militância partidária. Um trajeto ilustrativo desse padrão é o caso do dirigente da associação Hoctempore, de Pelotas. Ele tem 34 anos, é filho único e natural de Herval, onde o pai trabalha com comércio de carro e a mãe é professora do ensino fundamental. Durante o segundo grau, deslocou-se para a cidade de Pelotas, onde se formou em Eletromecânica pela Escola Técnica e em Direito pela Universidade Federal. Seus pais eram adeptos do PDT, mas ele iniciou sua participação política através do grêmio estudantil e, depois, da militância no Partido dos Trabalhadores (PT), integrando a "tendência" chamada de "democracia socialista". Como ele mesmo salienta, foi a "participação político-partidária" que o conduziu ao "movimento ambiental", no sentido de que foi com base na "aproximação ideológica" com ambientalistas do Centro de Estudos Ambientais (CEA), também filiados ao PT, que ele decidiu integrar tal associação. Desse modo, durante a formação universitária ocupou posição de direção simultaneamente no Diretório Central de Estudantes e no Centro de Estudos Ambientais (CEA), além de participar da "setorial de meio ambiente" do PT em nível estadual. Foi com base nesse trajeto de militância simultânea no PT e no CEA que ocupou a pasta de secretário municipal de Qualidade Ambiental, durante a administração petista no município de Pelotas (2001-2004). Todavia, durante o processo de sucessão do então prefeito e candidato à reeleição, tomou uma posição favorável à reeleição dele, contrariando a decisão de outras lideranças do CEA que, em função de atritos com o então prefeito, haviam decidido indicar outro candidato petista para a reeleição. Com isso, desligou-se da associação, criou a Hoctempore e, com base nos vínculos estabelecidos de longa data no PT, assumiu um cargo no Ministério do Meio Ambiente. Atualmente, ele é um dos principais articuladores de uma rede de ONGs voltadas à defesa do "bioma pampa", à qual já conta com a adesão de aproximadamente oitenta associações ambientalistas do estado. Disso resulta uma concepção do movimento ambientalista como devendo estar associado à política partidária. Ou seja, a única forma de unificar os objetivos e estratégias de luta das organizações e mobilizações ambientalistas é, necessariamente, através de uma orientação comum para a intervenção no âmbito da política partidária. O que fundamenta essa imbricação da "política ambiental" com a "partidária" é uma concepção militantista da própria política partidária, no sentido de que esta deve estar sempre associada a outras esferas de militância (Coradini, 2002).

No outro extremo se encontram os padrões de carreiras representados pelos que atuam como "assessores técnicos" das empresas de celulose e do próprio governo do estado. É interessante observar que, no caso da administração atual, os principais técnicos que tiveram uma participação destacada na formulação da proposta de zoneamento ambiental não são os funcionários dos órgãos responsáveis pela elaboração das políticas de gestão ambiental. Trata-se de técnicos de "fora" da administração estadual que, no entanto, têm uma longa experiência na assessoria tanto aos órgãos governamentais diretamente envolvidos com tal política quanto às empresas de celulose envolvidas. Um bom exemplo disso é o caso do relator do documento "Parecer sobre o zoneamento ambiental para a silvicultura", elaborado pela Câmara Técnica Permanente de Biodiversidade e Política Florestal da Sema. Trata-se de um professor universitário aposentado, com graduação, mestrado e doutorado em engenharia florestal, cujo exercício profissional foi marcado pela articulação do ensino universitário com a assessoria a órgãos públicos e empresas privadas do setor madeireiro. Seu próprio ingresso no curso de Engenharia Florestal foi fortemente influenciado pela família de origem. Isso porque seu avô materno e seu pai eram funcionários do Instituto Nacional do Pinho, órgão público que depois se tornou uma unidade do IBDF e depois do Ibama. Para ele isso é uma demonstração do quanto tem "uma história florestal já de origem, de nascimento". Todavia, foi com base nos vínculos estabelecidos através de seu pai, desde a infância, com o setor florestal e, principalmente, com os funcionários que trabalhavam em tal órgão público, que sua "história florestal" teve início e progresso. Ele ingressou na universidade de Santa Maria no curso de Engenharia Florestal influenciado pela promessa de um dos presidentes do Instituto Florestal do Pinho de que conseguiria uma bolsa de estudo. Assim, dois anos após a conclusão do curso universitário, ingres- 
sou logo no corpo docente da universidade, fazendo em seguida mestrado e doutorado na mesma área.

Com base em sua atuação como professor e pesquisador, ele ampliou seu exercício profissional como engenheiro florestal através de convênios e da prestação de serviços de consultoria e assessoria técnica para órgãos federais como o Ibama, bem como para administrações públicas na gestão de atividades vinculadas ao setor florestal. Tal atuação esteve articulada também à participação na Associação Gaúcha de Engenheiros Florestais desde sua criação em 1976, no Crea, como conselheiro de 1996 a 2002 e, mais recentemente, na criação da ONG Amigos da Floresta em 2002. Isso constituiu também uma das bases principais de sua atuação como assessor técnico de diversas empresas madeireiras e, nos últimos anos, das que estão investindo na ampliação do plantio de eucalipto no estado. É importante ressaltar que os vínculos estabelecidos com lideranças de organizações partidárias no decorrer de seu itinerário profissional são explicados sob o prisma das "relações de amizade" e não do interesse político e ideológico. É sob essa perspectiva que salienta seu apoio e sua participação em sucessivas campanhas eleitorais a uma das principais lideranças do PMDB estadual. Foi através desses vínculos tanto com o setor público quanto com o setor industrial que participou da elaboração do Inventário Florestal em 2001 (ainda na administração do PT) e se tornou o coordenador do Programa Floresta-Indústria RS (durante o governo do PMDB). Tal programa resultou de um convênio firmado em 2003 entre o estado do Rio Grande do Sul, por intermédio da Secretaria de Estado da Agricultura e do Abastecimento (SAA) e da Secretaria Estadual do Meio Ambiente (Sema-RS), do Centro das Indústrias do Rio Grande do Sul (Ciergs) e da Universidade Federal de Santa Maria (UFSM), por intermédio da Fundação de Apoio à Tecnologia e Ciência (Fatec), para realizar os estudos necessários para a implantação de um programa floresta-indústria no RS. Com base nesses vínculos anteriores, foi convidado pelo responsável da Secretaria do Desenvolvimento e dos Assuntos Internacionais para atuar como assessor técnico junto à atual administração estadual na questão dos investimentos florestais e tem demonstrado uma participação destacada na elaboração da proposta de zoneamento ambiental da atividade de silvicultura.

Numa posição intermediária entre esses dois extremos está o padrão de carreira característico dos funcionários da Sema, Fepam e FZB. Como já foi salientado anteriormente, existem fortes indícios de que os "técnicos" da burocracia estatal têm desempenhado um papel secundário na formulação de tal política. Por um lado, pelo fato de as posições-chave na elaboração da proposta de zoneamento ambiental estarem a cargo de assessores técnicos "externos" que foram "convidados" pelos responsáveis da administração estadual. Por outro, pelas notícias veiculadas sobre a desqualificação do documento elaborado pelos técnicos dos órgãos de proteção ambiental competentes, intitulado como excessivamente "restritivo" ao plantio de eucalipto, e sobre as represálias aos que manifestaram algum desacordo em relação ao documento proposto pela administração estadual. Um exemplo disso é o caso de um funcionário da Fundação Zoobotânica do Rio Grande do Sul (FZB), que é o conselheiro representante dos "técnicos" da Sema no Consema. Trata-se de um biólogo, com mestrado em ecologia pela UFRGS e doutorado em ecologia e recursos naturais pela Universidade Federal de São Carlos (UFSCar). Ele é oriundo de uma família com razoável situação econômica, pois seu avô paterno era dono de terras e o avô materno, funcionário público. Todavia, depois de contínuas investidas mal-sucedidas em vários setores, seu pai cursou advocacia e ingressou na política partidária, tornando-se vereador e presidente da Câmara Municipal da cidade de Vacaria, inicialmente pelo PMDB e depois pelo "antigo PDS", sendo que, para ele, "infelizmente só sobraram a herança cultural" e a "popularidade" que o pai tinha na cidade. Interligado a essa socialização política no âmbito familiar, ele teve uma trajetória escolar e profissional desde o início articulada com a participação em organizações políticas: primeiramente, através de grêmios estudantis e, depois, no centro acadêmico do curso de Biologia e no Partido dos Trabalhadores, principalmente durante as eleições.

No entanto, com exceção da presidência do grêmio estudantil de Vacaria, tais engajamentos não conduziram à ocupação de cargos de direção em tais organizações. O mesmo ocorreu com a sua participação em ONGs ambientalistas, pois chegou a trabalhar em uma delas como estagiário no tempo que estava concluindo o doutorado, mas depois parou de participar por "falta de tempo", pois já estava trabalhando na fundação, na Universidade de Santa Cruz (Unisc), e acabou indo para o "outro lado". Durante o curso universitário, atuou como bolsista de iniciação científica, investindo logo em seguida na qualificação profissional. Investiu também na carreira universitária, fazendo para isso três concursos na UFRGS, sendo que em um deles ficou em segundo lugar. No entanto, durante o período de vigência do concurso, não foi chamado e em 2002 ingressou na Fundação Zoobotânica no concurso promovido pelo governo do Partido dos Trabalhadores, quatro anos após a conclusão de seu doutorado. Quando isso ocorreu, ele já tinha atuado na docência e na pesquisa universitária, como professor substituto da UFRGS de 1993 a 1998 e como pesquisador da mesma instituição entre 2001 e 2002. Do mesmo modo, seu ingresso na "fundação" foi acompanhado pelo exercício de funções profissionais no ensino univer- 
sitário, como professor da Unisc de 2001 a 2003 e da Faculdade de Formação de Professores e Especialistas em Educação (Fafopee) de Camaquã. Atualmente trabalha na fundação e na Faculdade de Taquara (Faccat) com uma carga horária de oito horas. Além do trabalho na fundação e da docência universitária, desde o ano passado passou a prestar consultoria ainda de forma ocasional, na função de auditor de plantios florestais em todo o Brasil, fazendo a parte ambiental da certificação florestal. Tal itinerário conduz a uma concepção do "conhecimento técnico" como um dos elementos decisivos na gestão dos recursos ambientais. Assim sendo, ao contrário dos "políticos" e dos "ambientalistas", para ele o "técnico" é aquele que "pode dizer o que plantar e quanto pode plantar", se "é viável ou não", se "está sendo feito correto ou não", possibilitando dessa forma uma gestão racional dos recursos ambientais. Nesse sentido, como "ecólogo", faz questão de frisar sua diferença em relação aos "ecologistas", pois estes muitas vezes caem numa espécie de "histeria sem fundamento", de "ser contra por ser". Ao mesmo tempo, critica a atuação dos "políticos" na condução da proposta de zoneamento ambiental, pelo fato de nunca terem colocado "para sentar na mesma mesa os técnicos" das empresas e os da Sema. Segundo ele, se os políticos "tirassem a parte política e deixassem os técnicos conversarem entre si", estes certamente teriam "chegado a um consenso" sobre a proposta de zoneamento.

\section{Conclusões}

Semelhante ao que se tem observado no âmbito da constituição e do funcionamento das estruturas administrativas e burocráticas, também na análise dos padrões de carreiras dos que atuam na operacionalização das políticas de gestão ambiental a expertise e o conhecimento técnico não são o principal recurso utilizado pelos atores. Isso porque o exercício de funções de expertise em instâncias de proteção ambiental se insere num processo mais amplo de diversificação dos padrões de reconversão da formação escolar em competências e posições profissionais. Ela remete a dinâmicas de diversificação e de intensificação das modalidades de imbricação da formação e do exercício profissional com a participação política e o militantismo, contribuindo assim para a modificação das fronteiras vinculadas ao próprio exercício profissional (Oliveira, 2008a, 2008b). Como se pode ver, a caracterização dos principais padrões de carreiras que conduzem à ocupação de posições destacadas na elaboração da política de silvicultura possibilita evidenciar a diversificação das modalidades de utilização instrumental da formação técnica na formulação de políticas de gestão ambiental e suas relações com disposições e recursos acumulados pelos respectivos atores através de vínculos estabelecidos em diversos espaços sociais no decorrer de seus percursos biográficos. Desse modo, a capacidade de utilização do conhecimento técnico para a imposição de critérios na operacionalização da política de silvicultura se mostra estreitamente ligada à inserção simultânea em diversas redes sociais. Nesse sentido, aqueles que têm uma posição mais "intermediária", no sentido de relativamente "distanciada" das principais redes sociais que convergem para a formulação e a operacionalização de tal política, são justamente os que carecem de maior força e legitimidade na luta pelos critérios e procedimentos técnicos a serem aplicados em tal política.

Tais redes não se formam apenas através da consolidação de vínculos dentro do Estado, mas resultam também da participação em variadas esferas de atividade, possibilitando que se solidifiquem relações entre o campo público e o setor privado. Quando essas influências não são suficientes para impor suas respectivas decisões, verifica-se uma grande incapacidade de influenciar de modo decisivo a formulação dos critérios técnicos de aplicação dessas políticas. Talvez devido à "fragilidade" da posição dos técnicos nas atuais redes vinculadas à referida política, não se percebem muitos relatos por parte deles contendo reclamações sobre as pressões políticas sofridas atualmente no exercício de suas funções técnicas nos órgãos de proteção ambiental. Isso geralmente tem sido feito pelos ambientalistas, uma vez que tal denúncia constitui uma forma de confrontar as deliberações determinadas, como também por meio de pessoas que têm contatos tanto dentro quanto fora do setor público. Ou seja, mesmo tal discussão parecer ocorrer prioritariamente entre aqueles que dispõem dos recursos necessários para questionar os critérios e procedimentos técnicos vinculados à aplicação da política de silvicultura.

No que pese a relevância das abordagens "institucionalistas" na análise das políticas públicas, uma das dificuldades levantadas pela análise do programa de expansão do eucalipto diz respeito às relações entre a multiplicidade de referenciais ideológicos, a contínua modificação dos procedimentos e das medidas adotados na sua execução e a estrutura variável das redes de organizações e de atores inseridos em ordens sociais distintas e, particularmente, na esfera da política partidária, nas dinâmicas de sua formulação e operacionalização.

Diferente das análises que privilegiam a perspectiva "institucionalista" ou "organizacional", ao atribuir um peso elevado às instituições ou burocracias e aos processos políticos na compreensão das dinâmicas de operacionalização das políticas públicas, o desafio que nos propomos neste artigo foi o de utilizar uma abordagem "processualista" e "relacional". Tal abordagem 
enfatiza os processos diferenciados de configuração das políticas públicas em função dos vínculos e das influências recíprocas entre mecanismos político-institucionais e dinâmicas de inserção em múltiplas redes e esferas sociais dos respectivos atores envolvidos com sua formulação e implementação. Em consonância com isso, demonstrou-se que a existência e o funcio- namento das instituições administrativas e burocráticas de formulação e implementação de políticas de proteção ambiental, mais especificamente àquelas vinculadas à Secretaria Estadual de Meio Ambiente, estão profundamente imbricadas com clivagens políticoideológicas relacionadas à dinâmica político-eleitoral e mais amplamente à esfera da política partidária.

\section{Referências}

ACSELRAD, Henri. O movimento de ressistência à monocultura do eucalipto no norte do Espírito Santo e extremo sul da Bahia - uma sociologia da recusa e do consentimento em contexto de conflito ambiental. In: CONGRESSO ANUAL DA SOCIEDADE BRASILEIRA DE SOCIOLOGIA, XIII, 2007, Recife. Recife, Anais da SBS, 2007. ALONSO, Ângela; COSTA, Valeriano. Ciências sociais e meio ambiente no Brasil: um balanço bibliográfico. BIB, Anpocs, n. 53, 2002, p. 35-78.

ANDREOLI, C. V. Principais resultados da política ambiental brasileira: o setor público. Revista de Administração Pública, Rio de Janeiro, 1992, n. 26 (4), p. 10-31.

ANQUENTIN, V. Produire une politique municipale de l'environnement: la regulation des interactions des acteurs locaux par 1'“expertise” In: HAMMAN, P.; MÉON, J-M.; VERRIER, B. Discours savants, discours militants: mélange des genres. Paris: L'Harmattan, 2002, p. 129-151.

ARRETCHE, M. Capital social, política partidária e racionalidade dos atores. In: $5^{\circ}$ ENCONTRO DA ASSOCIAÇÃO BRASILEIRA DE CIÊNCIA POLÍTICA. Belo Horizonte, UFMG, 26 a 29 de junho de 2006.

BOURDIEU, P. La distinction. Critique sociale du jugement. Paris: Minuit, 1979.

Le sens pratique. Paris: Minuit, 1980.

BOLTANSKI, L. O diploma e o cargo: relações entre o sistema de produção e o sistema de reprodução. In: CAtani, A.; NOGUeIRA, M. A. (Orgs.). Pierre Bourdieu: escritos da educação. Petrópolis, RJ, Vozes, 1998.

Classificação, desclassificação, reclassificação. In: CAtAni, A.; NOGUEIRA, M. A. (Orgs.). Pierre Bourdieu: escritos da educação. Petrópolis: Vozes, 1998.

COLLOVALD, A. Et. Alli. (Dir.). L'humanitaire ou le management des dévouements. Enquête sur un militantisme de "solidarité internationale" en faveur dur Tiers-Monde. Rennes: PUR, 2002.

CONNIFF, M. L. A elite nacional. In: HEINZ, F. M. Por outra história das elites. São Paulo: FGV, 2006, p. 99-121.

CORADINI, O. L. "Crise" conjuntural das políticas "sociais" ou de referenciais. Ensaios FEE. Porto Alegre, (15) 2, p. 489-510, 1994.

Escolarização, militantismo e mecanismos de 'participação' política. In:HEREDIA, B., TEIXEIRA, C., BARREIRA, I. (Orgs.). Como se fazem eleições no Brasil. Rio de Janeiro: Relume-Dumará, 2002, p. 103-153.

Panteões, iconoclastas e as ciências sociais".
In: FELIX, Loiva Otero; ELMIR, Cláudio Pereira. (Orgs.) Mitos e heróis: construção de imaginários. Porto Alegre: Ed. Universidade/UFRGS,1988, p. 209-235.

DEZALAY, Yves; GARTH, Bryan. La mondialisation des guerres de palais. La restructuration du pouvoir d'État en Amérique Latine, entre notables du droit et "Chicago Boys". Paris: Seuil, 2002.

FILLIEULE, O. Propositions pour une analyse processuelle de l'engagement individuel. Revue Française de Science Politique. Paris, février-avril, v. 51, n. 1-2, 2001, p. 199-215.

GALLET, G. L' Expertise, outil de l'activisme environnemental chez Greenpeace France. In.: HAMMAN, P.; MÉON, J-M.; VERRIER, B. Discours savants, discours militants: mélange des genres. Paris: L'Harmattan, 2002, p. 109-128.

JIMÉNEZ, M. Consolidation through institutionalisation? Dilemmas of the Spanish environmental movement in the 1990s. In: C. Rootes (Ed.) Environnmental movements: local, national and global. London: Frank Cass, 1999, 149-171.

LASCOUMES, P. L'éco-pouvoir: environnements et politiques. Paris: La Découverte, 1994.

LOUREIRO, M. R.; PACHECO, R. S. Formação e consolidação do campo ambiental no Brasil: consensos e disputas (1972-1992). Revista de Administração Pública, Rio de Janeiro, 1995, out/dez, v. 29, n. 4, p. 137-153.

LECHIEN, M-H. Aider les autres: trajectoires professionnelles, reconversions militantes et valorisation de la 'personne'". In: COLLOVALD, A. et. al. (Dir.). L'humanitaire ou le management des dévouements. Enquête sur un militantisme de "solidarité internationale" en faveur dur TiersMonde. Rennes: PUR, 2002.

LOVE, J. L.; BARICKMAN, B. J. Elites regionais. In: HEINZ, F. M. Por outra história das elites. São Paulo: FGV, 2006, p. 77-97.

MARQUES, E. C. Redes sociais, instituições e atores politicos no governo da cidade de São Paulo. São Paulo: Annablume/ Fapesp, 2003.

MENEZES, C. L. Emergência e evolução da política ambiental urbana no Brasil: do Estado Novo à Nova República. Revista de Administração Pública. Rio de Janeiro, 1995, jan/fev, v. 31, n. 1, p. 70-95.

MULLER, P. Les politiques publiques comme construction d'un rapport au monde. In: FAURE, A.; POLLET, G.; WARIN, P. (Dirs.) La construction du sens dans les politiques publiques, débats autour de la notion de référentiel. Paris: 
Éditions L’Harmattan, 1995, p. 153-177.

OLIVEIRA, W. J. F. Paixão pela natureza, atuação profissional e participação na defesa de causas ambientais no Rio Grande do Sul entre 1970 e início dos anos 2000. Porto Alegre, 2005. Tese (Doutorado em Antropologia Social) - Universidade Federal do Rio Grande do Sul.

- Manifestações, protestos e defesa de causas ambientais no Rio Grande do Sul. Projeto de Pesquisa, CNPq, 2007a.

Políticas públicas de gestão ambiental e modelos de "desenvolvimento regional": referenciais, atores e ações vinculadas ao plantio de eucalipto no Rio Grande do Sul. Projeto de Pesquisa, Fapergs, 2007 b.
Engajamento político, expertise e elites dirigentes do movimento ambientalista. Revista de Sociologia e Política, Curitiba: UFP, n. 30. [No prelo].

Gênese e redefinição do militantismo ambientalista no Brasil. Dados, Rio de Janeiro, 2008b (no prelo). PÉCAUT, D. Os intelectuais e a política no Brasil: entre o povo e a nação. São Paulo: Ática, 1990.

ROOTES, C. (Ed.) Environnmental movements: local, national and global. London: Frank Cass, 1999.

SVIRSKY, E.; CAPOBIANCO, J. P. R. (Orgs.) Ambientalismo no Brasil: passado, presente e futuro. São Paulo: Instituto Socioambiental, Secretaria do Meio Ambiente do Estado de São Paulo, 1997.

\title{
Meanings and social uses of expertise in the implementation of environmental management policies
}

\begin{abstract}
This article examines the meanings and the social logics in the use of expertise resources in public policies for environmental management. The analytical procedures were centered in the analysis of the social history of the environmental protection sector and in an inquiry into the diversity of spheres and social networks articulated with family, educational, political and professional histories of the actors involved in the execution of forestry public policies in the Rio Grande do Sul state. The results obtained demonstrate that the meanings and the use of expertise in such situation are associated to diverse standards of reconversion, educational and professional, in different spheres of activity, on the basis of previous and/or simultaneous bonds established with diversified networks of organizations and 'social movements'.
\end{abstract}

Key words: public policies; expertise; social networks; professional reconversion.

\section{Significados y usos sociales de la expertise en la implementación de políticas públicas de gestión ambiental}

\begin{abstract}
Resumen
Este artículo examina los significados y las lógicas sociales de utilización de recursos de expertise en las políticas públicas de gestión ambiental. Los procedimientos analíticos se concentraron en un análisis de la historia social del sector de protección ambiental y en la investigación de la diversidad de esferas y de redes sociales articuladas a las trayectorias familiares, escolares, militantes y profesionales de los actores enredados con la ejecución de la política de silvicultura en Rio Grande do Sul. Los resultados obtenidos demostraron que los significados y la utilización del expertise en tal situación están asociados a los padrones distintos de reconversión de la formación y del ejercicio profesional en diferentes esferas de actividad, con base en los vínculos anteriores y/o simultáneos establecidos con redes distintas de organizaciones y "movimientos sociales"
\end{abstract}

Palabras clave: políticas públicas; expertise; redes sociales; reconversión profesional.

Data de recebimento do artigo: 01-08-2008

Data de aprovação do artigo: 24-10-2008 